\title{
Characterization of Dissolved Organic Matter in Landfill Leachate during Two-Stage Membrane Bioreactor Treatment
}

\author{
S. Sanguanpak ${ }^{1}$, C. Chiemchaisri ${ }^{*}$, W. Chiemchaisri ${ }^{3} \&$ K. Yamamoto ${ }^{4}$ \\ 1-3 Department of Environmental Engineering/Center of Excellence for Environmental and Hazardous Waste Management, \\ Faculty of Engineering, Kasetsart University, Bangkok 10900, Thailand \\ Environmental Science Center, University of Tokyo, Tolgo 113, Japan
}

\begin{abstract}
Landfill leachate is a complex wastewater containing high concentration of dissolved organic matter (DOM). In this study, DOM in raw leachate and treated water from pilot-scale two-stage membrane bioreactor (MBR) installed at solid waste disposal site were investigated by using fractionation method, fluorescence excitation-emission matrix spectroscopy (FEEM) and fourieu transform infrared (FTIR). The fractionation results showed hydrophilic (Hyl) compound was the most abundant fraction in DOM of raw leachate, whereas the dominant fraction of DOM in mixed liquor inside MBR and its effluent was fulvic acid (FA). The fluorescent peaks of protein-like, humic and fulvic-like substances were detected in influent DOM, while the furorescence peaks of MBR and effluent DOM were humic and fulvic-like substances. From the FTIR results, absorption bands that could be related to humic acid (HA) and FA, were found in both MBR and effinent DOM. The characterization of DOM indicated that the most of $\mathrm{Hyl}$ and protein-like substances could be significan dy removed by microbial process in $M B R$. Furthermore, a part of humic substance (HA and FA) could be eliminated by microbial and filtration processes.
\end{abstract}

Keywords: Dissolved organic matter, membrane bioreactor, fractionation, landfill leachate

\subsection{INTRODUCTION}

Landfill leachate is a high strength wastewater consisting of dissolved organic matter (DOM) and total organic carbon [1]. DOM is often considered as a mixture of hydrophilic and humic substances with different molecular weight. Chernical composition in wastewater can play a significant role in its biodegradability, pollutant biotransformation, and performance of treatment process $[1,2]$, therefore the understanding of DOM characteristic is necessary to optimize the efficiency of leachate treatment system.

Membrane bioreactor (MBR) is an attractive treatment system for leachate treatment and reuse as it is a compact system and capable of complete solid removal, high pollutant removal efficiency, and lower sludge production when compared with conventional activated sludge [3]. Recently, two-stage MBR was developed by additional inclined plate separator tank [4] to minimize the operating biomass for the following aerobic reactor. The application of this system was applied to treat partially stabilize leachate without excess sludge withdrawal [5]. High treatment efficiency could be achieved along the operation period. Nevertheless, removal of $\mathrm{COD}$ was considered at moderate level in comparison with BOD. This phenomenon was also found in the leachate treatment by MBR with an airlift bioreactor due to an incapable treatment of hardly biodegradable DOM [6].

The correlations of DOM in leachate and their treatment have been investigated using several measutement methodologies $[7,8]$. However, there is still

" Corresponding to: C.Chiemchaisri (email; fengecc@ku.ac,th) 
inadequate information regarding DOM in leachate during MBR treatment, especially the relation between DOM characteristics and its removal in the process. In this study, the degradation, transformation, and removal of DOM due to biological and filtration treatment process were determined using various techniques (XAD-8 fractionation, FEEM and FTIR). The characterization results were provided a greater understanding of DOM removal efficiency during the treatment.

\subsection{RESEARCH METHODOLOGY}

\subsection{Leachate Samples Collection}

The two-stage MBR pilot-scale treatment unit [5] consists of an anoxic tank with incline tube followed by aerobic tank with submerged membrane module (Fig.1). Six modules of $0.4 \mu \mathrm{m}$ polyethylene (PE) hollow-fiber membrane (Sterapore SURTM) were installed inside aerobic tank to achieve the maximum treatment capacity of $2 \mathrm{~m}^{3} /$ day. The aeration was continuously supplied to maintain dissolved oxygen (DO) concentration of 3-4 mg/1. Mixed liquor suspended solids (MLSS) concentration was controlled in the range of $10-12 \mathrm{~g} / 1$ by re-circulating excess sludge from aerobic tank back to anoxic tank. Total hydraulic retention time (HRT) in the whole system (anoxic and aerobic stages) was maintained at 24 hours. The membrane permeate flux was kept constant under intermittent mode $(10 \mathrm{~min}$ on and off) whereas trans-membrane pressures (TMP) were recorded along the operation period. Chemical cleaning of membrane module was performed when the TMP exceeded the recommended value specified by the manufacturer.
Samples were taken from the following locations, i) leachate preparation tank, feeding wastewater was prepared by mixing fresh and stabilized leachate at 1:10 volumetric mixing ratio. The collected samples from this tank were termed as influent, ii) Aerobic tank, mixed liquor samples of leachate taken from aerobic tank were termed as MBR, iii) Treated water tank, the membrane permeate samples representing treated leachate collected from this tank were termed as cflluent.

\subsection{Analytical Methods}

Determinations of influent, MBR and effluent characteristics during treatment period in term of biochemical oxygen demand $\left(\mathrm{BOD}_{5}\right)$ and chemical. oxygen demand (COD) were performed following Standard Methods [9]. Dissolved organic matters (DOM) of samples were prepared by 1:10 dilution and filtration through a GF/C filter. All of DOM samples were analyzed for the parameters described as follows.

Dissolved organic carbon (DOC) was measured using Shimadzu TOC-5000 total organic carbon analyzer. UV absorbance at $254 \mathrm{~nm}$ (UV ${ }_{254}$ ) was determined by Hach DR/4000U spectrophotometer with a quartz cell, $U_{254}$ analytical results were employed to calculate specific UV absorbance $\left(\mathrm{SUVA}_{254}\right.$ ), i.e. $U V_{254}$ dividesd by $\mathrm{DOC}$.

Hydrophobicity of DOM was determined by fractionation with Amberlite XAD-8 resin. DOM was fractionated into humic acid (HA), fulvic acid (FA) and hydrophilic (Hyl) fractions according to adopted fractionation method [1]. The concentration of each fraction was quantified by measuring its $\mathrm{DOC}$.

Fluorescence excitation-emission matrix (FEEM) spectroscopy of DOM was determined on a Jasco

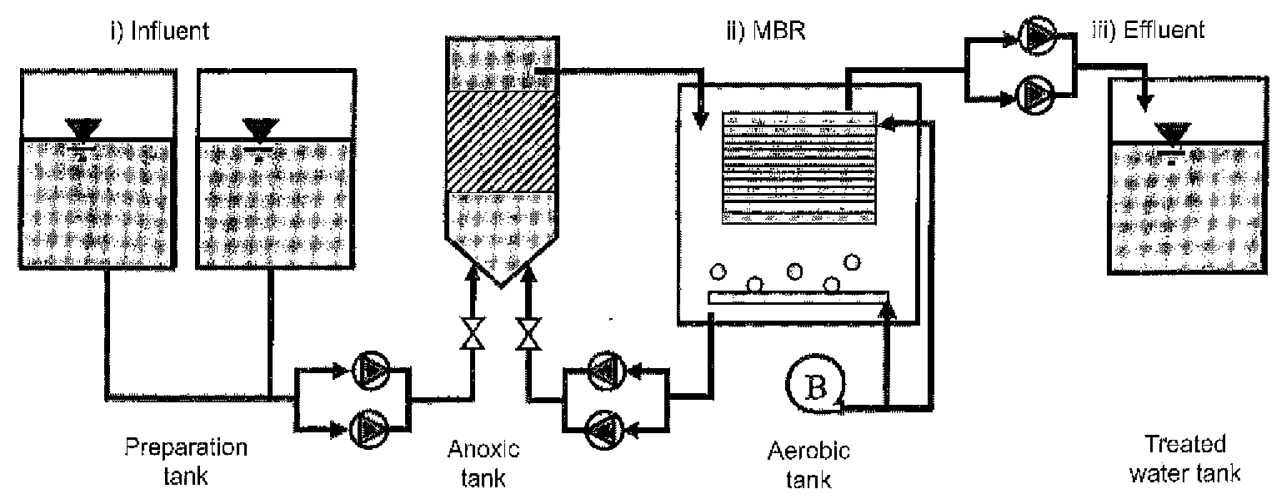

Figure 1 Schematic of two-stage MBR and sampling points 
FP-8200 spectrofluorometer using a $1 \mathrm{~cm}$ quartz cell. Before EEM analysis, all samples were diluted to DOC of $10 \mathrm{mg} / 1$ and adjusted to $\mathrm{pH} 7 . \mathrm{EEM}$ spectra were collected at an excitation ( $\mathrm{Ex}$ ) wavelength from $200 \mathrm{~nm}$ to $500 \mathrm{~nm}$ and emission (Em) wavelength from $250 \mathrm{~nm}$ to $600 \mathrm{~nm}$ with $5 \mathrm{~nm}$ increments. The spectra were scanned with a $5 \mathrm{~nm}$ slit bandwidths at a scan rate of $2,000 \mathrm{~nm} / \mathrm{min}$.

Fourier transform infrared (FTIR) was employed to determine the functional groups on a Perkin-Elmer spectrum spotlight FTIR imaging system with microATR technique. DOM samples were freeze-dried for 24 h undex $-50^{\circ} \mathrm{C}$. The FTIR spectra of powder samples were examined in a middle wavelength infrared of $4000-600 \mathrm{~cm}^{-1}$ with $4 \mathrm{~cm}^{-1}$ resolution.

\subsection{RESULTS AND DISCUSSION}

\subsection{Leachate and DOM Characteristics}

Table 1 presents the characteristics of leachates influent, MBR and effluent during the operation. The influent leachate was classified as moderate biodegradable with average COD of $9,400 \mathrm{mg} / \mathrm{l}, \mathrm{BOD}$ of $3,891 \mathrm{mg} / \mathrm{l}$ and DOC of $3,695 \mathrm{mg} / 1$ [10]. After leachate treatment the effluent concentration of COD, BOD and DOC were reduced to an average value of $1,313 \mathrm{mg} / 1,133 \mathrm{mg} / 1$ and $502 \mathrm{mg} / 1$ respectively. Accordingly, about $86 \%$ of COD and DOC removals and $96 \%$ of BOD removal efficiency were achieved. Comparing between $M B R$ and effluent characteristics, their qualities were not differ much in term of DOC (about 10\%) but there was some greater difference in terms of BOD and COD (40-80\%) which indicates the effect of membrane filtration in retaining particulate matter contributed in both $B O D$ and COD measurements.
Specific UV absorbance at $254 \mathrm{~nm}$ (SUVA ${ }_{254}$ ) of effluent DOM showed a significant increase in comparison with that of influent DOM from 0.51 to $2.84 \mathrm{lmg}^{-1} \mathrm{~m}^{-1}$, whereas it was similar to MBR DOM $\left(2.76 \mathrm{lmg}^{-1} \mathrm{~m}^{-1}\right)$. SUVA 254 is a parameter that represents the ratio of aromatic carbon content to total DOM. The low SUVA 254 indicates the low content of aromatic organic carbon. In this study, the result of increased $\mathrm{SUVA}_{254}$ indicated that the MBR treatment process was probably incapable for removing aromatic carbon compounds from the influent DOM. The characterization results identified that the leachate DOM was significantly eliminated by the treatment process and remaining DOM in effluent was higher in a form of aromatic carbon compound than that in the influent.

\subsection{DOM Fractionation}

The fractionation distribution and DOC concentration of HA, FA, and Hyl fraction of DOM samples are presented in Table 2 and Fig. 2. DOM fraction could be used to characterize the group of organic compounds containing in water sample. For instance, humic substance consisted mainly of bio-refractory and aromatic organic substances, while Hyl fraction had lower aromatic organic content and easily degradable component [1]. The DOC of the influent was mainly composed of the Hyl fraction $(68 \% \mathrm{w} / \mathrm{w})$, followed by $23 \%$ of $\mathrm{FA}$ and $9 \%$ of HA fraction, whereas the MBR and effluent were dominated by FA fraction accounting for $44 \%$ and $50 \%$. The Hyl fraction was found as secondary group at $33 \%$ and $36 \%$, and the HA fraction was accounted for $22 \%$ and $13 \%$ respectively. This suggested the significant increase of

Table 1 Characteristic of leachate collected samples

\begin{tabular}{lccc}
\hline Parameter & Influent & MBR & Effuent \\
\hline $\mathrm{pH}$ & 6.98 & 8.60 & 8.85 \\
$\mathrm{BOD}_{5}(\mathrm{mg} / 1)$ & $3,891(63)$ & $580(21)$ & $133(32)$ \\
$\mathrm{COD}(\mathrm{mg} / 1)$ & $9,400(200)$ & $3,400(346)$ & $1,313(241)$ \\
$\mathrm{DOC}(\mathrm{mg} / 1)$ & $3,695(25)$ & $567(7)$ & $502(8)$ \\
$\mathrm{UV}_{254}\left(\mathrm{~cm}^{-1}\right)$ & 18.86 & 15.24 & 14.29 \\
$\mathrm{SUVA}_{254}\left(\mathrm{lmg}^{-1} \mathrm{~m}^{-1}\right)$ & 0.51 & 2.76 & 2.84 \\
\hline
\end{tabular}

$\mathrm{N}=3$, samples collected in January 2012 
the hydrophobic fraction in terms of FA and HA after the MBR treatment

During the reatmont, the $-T y l$ concentration was reduced from $2,215 \mathrm{mg} / 1$ to $183 \mathrm{mg} / 1 \mathrm{in}$ MBR and 162 $\mathrm{mg} / \mathrm{l}$ in the effluent, indicating that the Hyl fraction was obviously removed after MBR treatment. The Iyl removal could be explained by biodegradation reaction of activated sludge since this organic fraction has high biodegradable characteristic, whereas the lower removal efficiency was achieved for the FA and HA fractions. The FA concentration was reduced from $719 \mathrm{mg} / 1$ to $254 \mathrm{mg} / \mathrm{l}$ in MBR and $225 \mathrm{mg} / 1$ in the effluent, and the HA was reduced from $207 \mathrm{mg} / 1$ to $100 \mathrm{mg} / 1 \mathrm{in} \mathrm{MBR}$ and $40 \mathrm{mg} / 1$ in the effluent. The biological treatment for high molecular weight (MW) compounds such as humic substance has been identified as originated from bio-sorption in the first step because the micro-organisms cannot directly uptake these high MW compounds [11]. In this study, the FA fraction was found more efficiently removed than that of the HA fraction in the biological MBR treatment which was probably due to less complex molecular structure of FA compared to that of $\mathrm{HA}$. On the other hand, the HA fraction was efficiently removed during membrane filtration. The resulting of the reduced HA fraction could be possibly relating to adsorption of compounds onto the membrane surface. The increased hydrophobicity property of membrane surface by foulant layer accumulation could result in a highly rejection of the strongly hydrophobic characteristic of the IHA fraction [12].

Table 2 DOC concentrations of DOM fractions along the treatment process

\begin{tabular}{lccc}
\hline Fraction & $\begin{array}{c}\text { Influent } \\
\text { DOM }\end{array}$ & $\begin{array}{c}\text { Mixed } \\
\text { liquor } \\
\text { DOM }\end{array}$ & $\begin{array}{c}\text { Effuent } \\
\text { DOM }\end{array}$ \\
\hline HA (mg/1) & 207 & 100 & 40 \\
FA (mg/1) & 719 & 254 & 225 \\
Hyl (mg/1) & 2,215 & 183 & 162 \\
\hline
\end{tabular}

\subsection{Fluorescence EEMs of DOM}

Fluorescence EEM was used to provide additional information of fluorescence properties of DOM in leachate during the MBR treatment. There were six

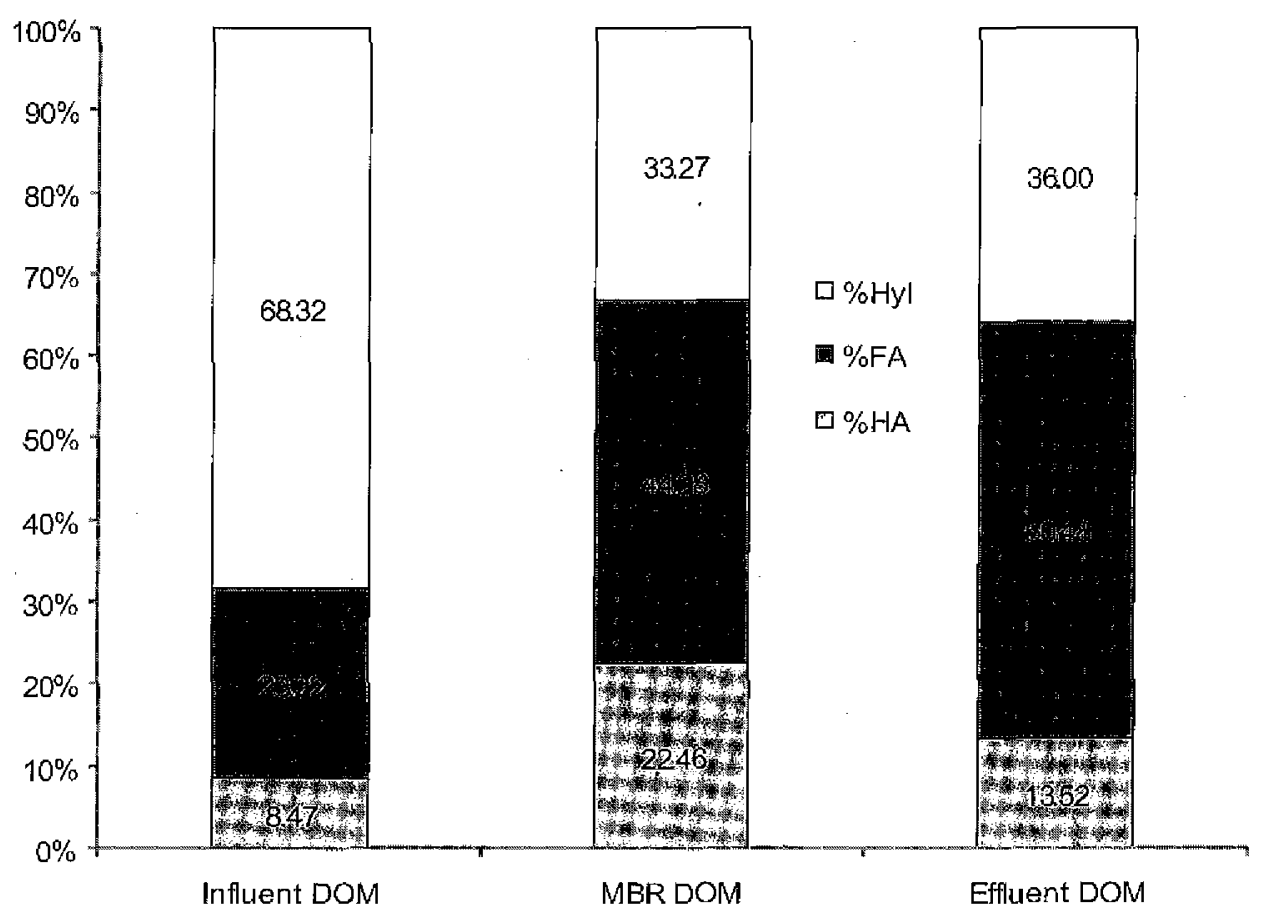

Figure 2 Percentages of DOM fractions distribution in influent, MBR and effluent 
principal fluorescence peaks that are illustrated in Fig. 3. Based on the fluorescence EEMs of DOM in landfill leachate reported in previous research [13], the putative origin of each fluorescence peak obtained from this study are identified. For the influent DOM, the fluorescence peak at $\mathrm{Ex} / \mathrm{Em}=270-280 / 300-310$ (peak A) was attributed to be a tyrosine-like substances. The fluorescence peal $\mathrm{s}$ at $\mathrm{Ex} / \mathrm{Em}=230-240 / 330-340$ (peak B) and at $\mathrm{Ex} / \mathrm{Em}=280-290 / 310-340$ (peak C) were related to tryptophan-like substances. The peak at Ex/Em $=290-310 / 400-420$ (peals D) was suggested to be humiclike substances and iabeled as fulvic acid like [7]. There were two new fluorescence peaks in the MBR DOM, the peals at $\mathrm{Ex} / \mathrm{Em}=220-230 / 400-420$ (pcals $\mathrm{E}$ ) whidl was similar to humic-like substances, and another peak at Ex/ $\mathrm{Em}=250-260 / 460-470$ (peak F) which is still unclear but possibly related to the pyrenyl functional group or humic-like substances. The fluorescence peaks of proteinlike substance (peak $A, B$, and C) mostly disappeared from the system after the biological treatment process, whereas the humic-like substances (peak D) were shifted to the longer wavelengths as compared to that of the influent DOM. The extended of wavelengths implied an increasing of molecular size, aromatic polycondensation, and degree of humification [2]. As for the effluent DOM, the location of humic-like substances at fuorescence peak $D$ were again shifted as compared to that of the MBR DOM, and part of humic-like substances at peak $E$ was removed after the membrane filtration. 'The remaining
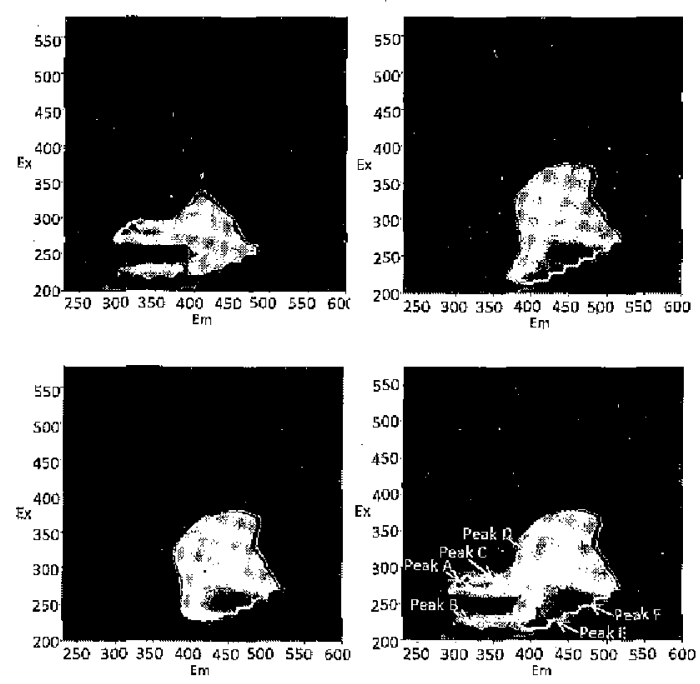

Figure 3 Fluorescence EEMs ofDOM samples (a) Influent DOM, (b) MBR DOM, (c) Effluent DOM, and (d) summary of fluorescence peak position of fluorescence peak $F$ demonstrated non-biodegradable character which could not be removed in the treatment system [13]. The FEEM results indicated that the MBR treatment system could remove most of protein-like substances and some part of humic-iike substances.

\subsection{FTIR OF DOM}

The FTIR spectra of DOM samples are shown in Fig. 4 and the general assignments of the main FTIR spectra are detailed in Table 3. The FTIR spectrum pattern of the influent DOM was rather different from that in the MBR and effluent DOM, while the quite similar FTIR spectrum was found in both of the MBR and effluent DOM, that explained the transformation of functional groups and molecular structures importantly occurred due to the biological treatment process. For the influent DOM, it was found the absorbance bands at $2950-2880 \mathrm{~cm}^{-1}$ could be related to $\mathrm{C}-\mathrm{H}$ stretching bond from carboxylic group in leacahte which was also obtained in the MBR and effluent DOM. Furthermore, the absorbance bands that detected only in the infiuent DOM were the absorbance band at 1565,1415 , and $1130-1000 \mathrm{~cm}^{-1}$. This absorbance bands were probably related to $\mathrm{N}-\mathrm{H}$ in plane second band of amides, stretch of carboxylic acid groups, and C-O stretching of carbohydrate or polysaccharide-like substance respectively. For the MBR and effuent DOM, the FTIR spectrum showed the absorbance bands of the aromatic $C \mathrm{C}$ stretch at $1620-1580 \mathrm{~cm}^{-1}$ indicating the existence of aromatic structures and the bands between $1700-1630 \mathrm{~cm}^{-1}$ illustrating the $\mathrm{C}=\mathrm{C}$ stretching of carboxylic acid and amide group in that DOM. This finding on absorbance bands indicated the presence of fuivic acid and humic acid which have relatively strong absorbance band at $1710-1690 \mathrm{~cm}^{-1}$ and $1630 \mathrm{~cm}^{-1}$ [2] Moreover, the absorbance bands at $2550-2540 \mathrm{~cm}^{-1}$ and $1400 \mathrm{~cm}^{-1}$ could be attributed to carboxylate ions and $\mathrm{N}-\mathrm{O}$ stretch of nitrate, indicating the degradation of carboxylic acids and amide groups in this process. Nevertheless, the absorbance bands at 834 and 705 $\mathrm{cm}^{-1}$ indicated the remaining of amide group of the treated DOM. The FTIR spectra results showed the significant increasing of aromatic and carboxylic group that could be related to humic substances and partial degradation of carboxylic acid and amide group in the MBR process for leachate treatment. 
Table 3 General assignments of liTIR spectra $[7,8]$

\begin{tabular}{|c|c|}
\hline $\begin{array}{l}\text { Wave length } \\
\left(\mathrm{cm}^{-1}\right)\end{array}$ & Assignment \\
\hline $2950-2850$ & $\begin{array}{l}\text { Asymmetncal and symmetrical } \\
\text { stretching of methyl and methylen } \\
\mathrm{C}-\mathrm{H}\end{array}$ \\
\hline $2850-2500$ & Carboxylate ion \\
\hline $1725-1640$ & $\mathrm{C}=\mathrm{O}$ stretching of carboxylic acids \\
\hline $1620-1580$ & $\begin{array}{l}\text { Aromatic } \mathrm{C}=\mathrm{C} \text { double bonds that } \\
\text { are conjugated with } \mathrm{C}=\mathrm{C} \text { of } \mathrm{COO}\end{array}$ \\
\hline$: 570-1540$ & $\begin{array}{l}\mathrm{N}-\mathrm{H} \text { bending vibration of amide } \\
\text { group (amid-2) }\end{array}$ \\
\hline $1420-1410$ & $\begin{array}{l}\mathrm{O}-\mathrm{H} \text { vibration of carboxylic group } \\
\mathrm{C}-\mathrm{H} \text { deformation abutted upon } \\
\mathrm{C}=\mathrm{O}\end{array}$ \\
\hline 1400 & Nitrate \\
\hline $1120-1000$ & $\begin{array}{l}\mathrm{C}-\mathrm{O} \text { stretching of carbohydrates, } \\
\text { esters and polysaccharide of } \\
\text { polysaccharide-like substances }\end{array}$ \\
\hline $850-650$ & $\mathrm{C}-\mathrm{H}$ vibration of $\mathrm{N}-\mathrm{H}$ out of plane \\
\hline
\end{tabular}

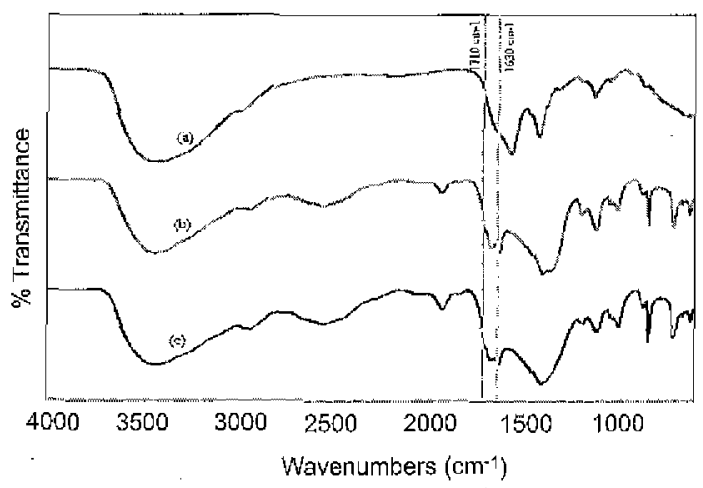

Figure 4 FTIR spectra of DOM samples of Influent DOM (a), MBR DOM (b), and Effluent DOM (c)

\subsection{CONCLUSIONS}

Dissolved organic matter of landfill leachate composed of various fractionated components. The DOM classifed as $\mathrm{Hyl}$ fraction and protein-like substances could be efficient removed by biological activities in MBR process. The humic-like substances and its fractions ( $\mathrm{HA}$ and $\mathrm{FA}$ ) was observed as the most abundant fractions in MBR and effluent DOM, and filtration process in MBR also contributed to significant removal of their fractions.

\section{ACKNOWLEDGEMENT}

This research was financially supported by the Japan International Cooperation Agency (JICA) under the Research and Development for Water Reuse Technology in Tropical Region (Water InTro) Project.

\section{REFERENCES}

[1] P.J. He, J. Xue, L. Shao, G. Li, D. Lee. 2006 Dissolved organic matter (DOM) in recycled leachate of bioreactor landfill. Water Res. 40 : $1465-1473$.

[2] K. Kang, H. S. Shin, H. Park, 2002. Characterization of humic substances present in landfill leachates with differerent landfill ages and its implications. Water Res. 36 : 4023-4032.

[3] W. Y. Ahn, M. S. Kang, S. K. Yim, K. H. Choi. 2002. Advanced landfill leachate treatment using an integrated membrane process. Desalination. $149: 109-114$.

[4] C.H. Xing, K. Yamamoto \& K. Fukushi. 2006. Performance of an inclined-plate membrane bioreactor at zero excess sludge discharge. J. Membr. Sci. $275: 165-175$.

[5] C. Chiemchaisri, W. Chiemchaisri, P. Nindee, C. Y. Chang, K. Yamamoto. 2011. Treatment performance and microbial characteristics in two-stage membrane bioreactor applied to partially stabilized leachate. Water Sci. Terhnol. $64: 1064-1072$.

[6] S.Chen,J. Liu. 2006. Landfill leachate treatment by MBR: Performance and molecular weight distribution of organic contaminant. Chin. Sci. Bull. $51: 2831-2838$. 
[7] S. L. Huo, B. D. Xi, H. C. Yu, H. L. Liu. 2009. Dissolved organic matter in leachate from different treatment processes. Water Environ. J. $23: 15-22$.

[8] L. Bu, K. Wang, Q.L. Zhao, L. L. Wei, J. Zhang, J. C. Yang: 2010. Characterization of dissolved organic matter during landfill leachate treatment by sequencing batch reactor, aeration corrosive cell-fenton, and granular activated carbon in series, J. Hazard. Mater. 179 : 1096-1105.

[9] APHA. 1998. Standard Methods for the Examination of Water and Wastewater. 20th ed. American Public Health Association, Washington, DC.
[10] S. Renou, J.G. Givaudan, S. Poulain, F. Dirassouyan, P. Moulin. 2008. Review Landfill leachate treatment: Review and opportunity. J. Hazard. Mater. 150: 468-493.

[11] M. Esparza-Soto, P. Westerhoff. 2003. Biosorption of humic and fulvic acids to live activated sludge biomass. Water Res. 37 :23012310.

[12] P. Xu, J.E. Drewea, T.U. Kim. 2006. Effect of membrane fouling on transport of organic contaminants in NF/RO membrane application. J. Membr. Sci. 279 : 175-186.

[13] F. Lu, C. IJ. Chang. D. J. Lee, P. J. He, L. M. Shoa, A. Su, 2009. Dissolved organic matter with multi-peak fluorophores in landfill leachate. Chemosphere. $74: 575-582$. 